\section{Embolic complications associated with endoscopic injection of cyanoacrylate for bleeding duodenal ulcer}

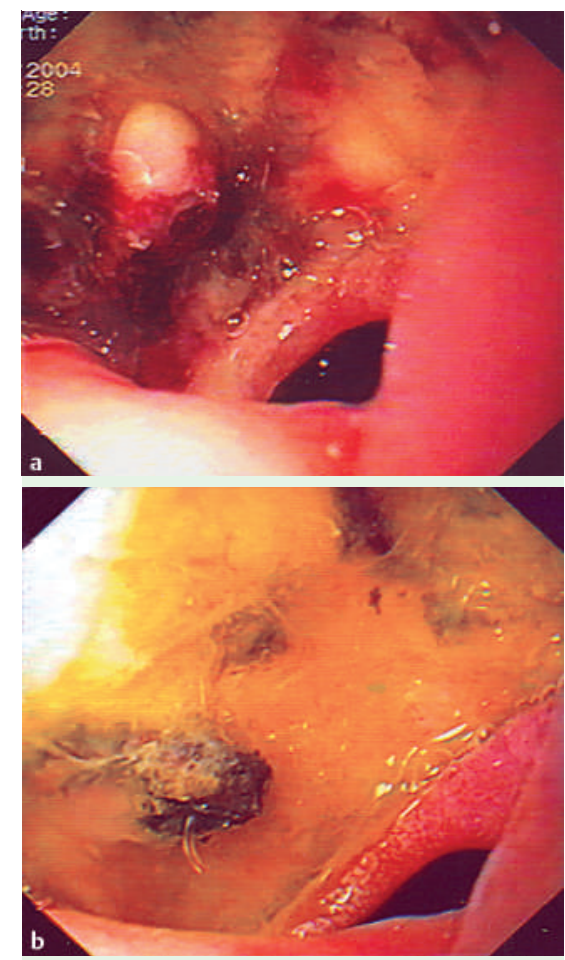

Fig. 1 Ulcer on the anterosuperior bulb wall, on 24-hour second-look endoscopy: a with visible vessel; b after second NB2C treatment.

An 87-year-old man with severe cardiac disease, on treatment with an antiplatelet agent, was admitted to our department with acute melena, in a hemodynamically unstable state, and with a hemoglobin level of $6 \mathrm{mg} / \mathrm{dL}$. Emergency endoscopy revealed an extensive ulcer in the anterosuperior bulb wall with pulsatile bleeding. This was initially injected with epinephrine and fibrin glue (as it was a deep ulcerated lesion). When this failed to stop the bleeding, we used a $1: 0.6$ mixture of $\mathrm{N}$-butyl-2-cyanoacrylate (NB2C; Histoacryl) and lipiodol, which did stop it. At second-look endoscopy, a large pulsatile vessel was still present ( $\bullet$ Fig. 1 a), which was permanently occluded after a second NB2C application ( $\bullet$ Fig. 1 b). Five days later, the patient developed febrile peaks $\left(40^{\circ} \mathrm{C}\right)$ without complaints but with leukocytosis and a five-fold increase in levels of aminotransferases, amylase, and lipase. A thoracoabdominal computed tomography (CT) scan showed linear opacification of the common hepatic artery
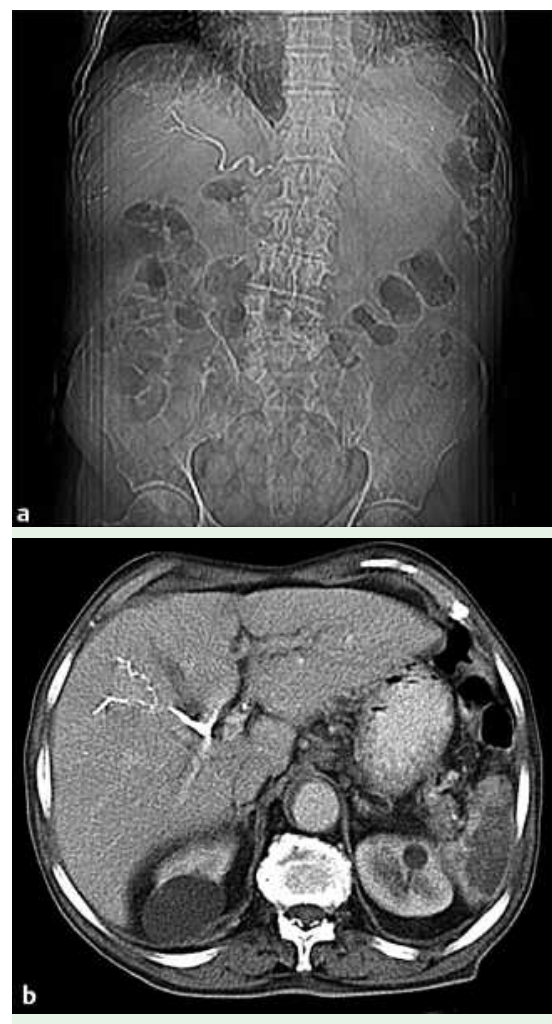

Fig. 2 Abdominal CT scan showing radiopaque material in a the common hepatic artery and $\mathbf{b}$ its right branch and some splenic branches. Multiple areas of splenic infarctions are visible in $\mathbf{b}$.

( $\bullet$ Fig. 2 a), its right branch, and some splenic branches ( Fig. $\mathbf{2}$ b), with a heterogeneous area in the spleen ( $\bullet$ Fig. 2 b) and in the pancreatic head lesions. The patient started treatment with an intravenous broad-spectrum antibiotic, along with nutritional support measures, and the liver test parameters improved considerably. Blood cultures failed to isolate any bacterial strain. The patient was discharged on day 15 . Sixmonth imaging follow-up showed remarkable improvement.

Bleeding peptic ulcer is still the main cause of upper gastrointestinal hemorrhage [1]. Several endoscopic hemostatic methods of similar efficacy are currently available [1]. The use of NB2C, a successful and well-established substance used in variceal hemorrhage, is still controversial in the context of bleeding peptic ulcer (๑ Fig. 3) highly suggestive of infarction

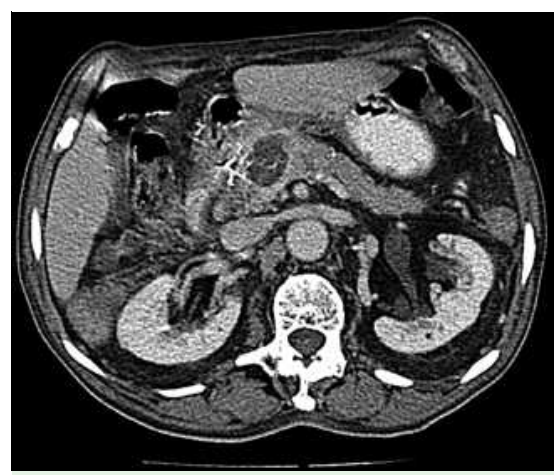

Fig. 3 Abdominal CT scan showing a heterogeneous area in the pancreatic head.

$[2,3]$. Encouraging results have shown it to have good hemostatic efficacy when conventional endoscopic techniques have failed to control bleeding [2,3]. However, it has been associated with severe embolization with infarction $[2,4,5]$. The present case highlights a potential adverse effect of cyanoacrylate use.

\section{Endoscopy_UCTN_Code_CPL_1AH_2AC}

P. Peixoto, P. Ministro, A. Sadio,

A. Castanheira, E. Cancela, R. Araújo,

A. Silva, A. Caldas

Gastroenterology Department,

São Teotónio Hospital, Viseu, Portugal

\section{References}

1 Huang CS, Lichtenstein DR. Nonvariceal upper gastrointestinal bleeding. Gastroenterol Clin North Am 2003; 32: 1053-1078

2 Repici A. et al. Adrenaline plus cyanoacrylate injection for treatment of bleeding peptic ulcers after failure of conventional endoscopic haemostasis. Dig Liver Dis 2002; 34: 349-355

3 Kok KY, Kum CK, Goh PM et al. Endoscopic hemostasis of upper gastrointestinal bleeding with histoacryl: last resort before surgery. Endoscopy 1996; 28: 256-258

4 Lee GH, Kim JH, Lee KJ et al. Life threatening intraabdominal arterial embolization after histoacryl injection for bleeding gastric ulcer. Endoscopy 2000; 32: 422-424

5 Vallieres E, Jamieson C, Haber GB et al. Pancreatoduodenal necrosis after endoscopic injection of cyanoacrylate to treat a bleeding duodenal ulcer: a case report. Surgery 1989; 106: $901-903$

Bibliography

DOI $10.1055 / \mathrm{s}-2007-995695$

Endoscopy 2008; 40: E126

() Georg Thieme Verlag KG Stuttgart · New York ISSN 0013-726X

\section{Corresponding author}

\section{P. C. P. Peixoto, MD}

Gastroenterology Department, São Teotónio Hospital, Av. Rei D. Duarte, 3504509 Viseu, Portugal Fax: +351-232-420591

paulacristinapeixoto@iol.pt 